\title{
Landscape of Eukaryotic Transmembrane Beta Barrel Proteins
}

Roumia, Ahmed F.; Theodoropoulou, Margarita C.; Tsirigos, Konstantinos D.; Nielsen, Henrik; Bagos, Pantelis G.

Published in:

Journal of Proteome Research

Link to article, DOI:

10.1021/acs.jproteome.9b00740

Publication date:

2020

Document Version

Peer reviewed version

Link back to DTU Orbit

Citation (APA):

Roumia, A. F., Theodoropoulou, M. C., Tsirigos, K. D., Nielsen, H., \& Bagos, P. G. (2020). Landscape of Eukaryotic Transmembrane Beta Barrel Proteins. Journal of Proteome Research, 19(3), 1209-1221.

https://doi.org/10.1021/acs.jproteome.9b00740

\section{General rights}

Copyright and moral rights for the publications made accessible in the public portal are retained by the authors and/or other copyright owners and it is a condition of accessing publications that users recognise and abide by the legal requirements associated with these rights.

- Users may download and print one copy of any publication from the public portal for the purpose of private study or research.

- You may not further distribute the material or use it for any profit-making activity or commercial gain

- You may freely distribute the URL identifying the publication in the public portal 


\section{The landscape of eukaryotic transmembrane beta}

\section{barrel proteins}

Ahmed F. Roumia ${ }^{a}$, Margarita C. Theodoropoulou ${ }^{a}$, Konstantinos D. Tsirigos $^{b c}$, Henrik Nielsen ${ }^{c}$ and Pantelis G. Bagos $^{a_{*} *}$

a Department of Computer Science and Biomedical Informatics, University of Thessaly, 35100 Lamia, Greece

${ }^{\mathrm{b}}$ Disease Systems Biology Program, Novo Nordisk Foundation Center for Protein Research, Faculty of Health and Medical Sciences, University of Copenhagen, Copenhagen, Denmark

${ }^{\mathrm{c}}$ Department of Health Technology, Section for Bioinformatics, Technical University of Denmark, Kgs Lyngby, Denmark

E-mail:pbagos@compgen.org

Abstract

Even though in the last few years several families of eukaryotic $\beta$-barrel outer membrane proteins (OMPs) have been discovered, their computational characterization and their annotation in public databases is far from complete. The PFAM database includes only very few characteristic profiles for these families and, in most cases, the profile Hidden Markov Models (pHMMs) have been trained using prokaryotic and eukaryotic proteins together. Here, we present for the first time a comprehensive computational analysis of eukaryotic transmembrane $\beta$-barrels. 12 characteristic pHMMs were built, based on an extensive literature search, that can discriminate eukaryotic $\beta$-barrels from other classes of proteins (globular and bacterial $\beta$-barrel ones), as well as between mitochondrial and chloroplastic ones. We built eight novel profiles for the chloroplastic $\beta$-barrel families that are not present in the PFAM database and, also, updated the profile for the MDM10 family 
(PF12519) in PFAM and split the porin family (PF01459) into two separate families, namely VDAC and TOM40.

Keywords

Eukaryota, Mitochondria, Chloroplast, Transmembrane, Beta barrels, Hidden Markov Model

\section{Introduction}

$\beta$-barrel outer membrane proteins (OMPs) are important components of the outer membranes of chloroplasts, mitochondria and Gram-negative bacteria. Eukaryotic $\beta$-barrel membrane proteins form one of the two main structural classes of integral membrane proteins. They exist exclusively in the outer membrane of chloroplasts and mitochondria ${ }^{1}$. They play a vital role in signaling and membrane biogenesis. They also carry out a series of significant cellular functions including acting as transporters, porins, enzymes, virulence factors and receptors ${ }^{2}$. $\beta$-barrel proteins play a crucial role in the connection of the double membrane-bound organelles with the rest of the cell. $\beta$-barrel channels arrange the movement of organellar pre-proteins that are synthesized in the cytosol towards the organelle and allow the flux of a large number of metabolites ${ }^{3-8}$. The presence of $\beta$-barrels in these organelles also supports the hypothesis that chloroplasts and mitochondria evolved from prokaryotic ancestors as the endosymbiotic theory suggests ${ }^{9}$. The OMPs also form a defensive line for Gram-negative bacteria against the invasion from pathogens and the subsequent infections, while, at the same time, performing a lot of crucial functions within the cell like cell signaling, adhesion and nutrient import ${ }^{10}$.

Mitochondria, being the powerhouse of the cell, preserve a continuous bidirectional movement of ATP, ADP, $\mathrm{NADH}$, ions and general metabolite flux through the mitochondrial outer membrane (MOM). The MOM is involved in the maintenance of the mitochondrial integrity, which may otherwise lead to halt of ATP generation, dysregulation of $\mathrm{Ca}^{2+}$ homeostasis, release of cytochrome c, apoptosis and several other irregularities ${ }^{11,12}$. The MOM contains a variety of proteins such as porins, enzymes for the lipid biosynthesis, components of the protein translocation machinery and other processes as well as proteins that control the morphology of the organelle ${ }^{13,14}$. Approximately $8-10 \%$ of the total mitochondrial proteins are found in the MOM ${ }^{15-17}$. A mitochondrial porin, the voltage-dependent, anion-selective channel (VDAC), is responsible for the movement 
of small molecules between the mitochondrion and the cytosol. TOM40 is part of the translocase of the outer membrane and acts as the channel that transports the pre-proteins during their import into the organelle ${ }^{18}$. SAM50 is an integral $\beta$-barrel protein of the outer membrane, conserved from bacteria (OMP85) all the way to humans ${ }^{6,9,19}$. MDM10 is a beta barrel outer membrane protein ${ }^{20}$. Also, it is considered to be a specific member of the SAM complex, which promotes the last steps of the TOM complex assembly by affecting the binding of TOM40 with TOM22 and other small TOM proteins ${ }^{21}$.

Chloroplasts have a unique role in plant cells as the site of photosynthesis and carbohydrate biosynthesis ${ }^{22}$. Two membranes, the inner and the outer, which comprise the envelope, separate spatially the chloroplast stroma from the cytoplasm ${ }^{23}$. The existence of diverse and effective transport mechanisms across the envelope is of essence to provide the cell with the compounds produced in the chloroplasts ${ }^{22}$. Electrophysiological studies, channel activity experiments, lipid-binding properties and phylogenetic analyses revealed eight voltage-gated channels at the outer membrane of chloroplasts, including OEP $21^{24}$, OEP $23^{25}$, OEP24 ${ }^{26,27}$, OEP $37{ }^{28}$, OEP40 29, TGD4 ${ }^{30},{\text { TOC } 75^{31} \text { and OEP80 }}^{32}$.

Our goal is to fully characterize the families of mitochondrial and chloroplast OMPs. Even though several of these families are already known in the literature (i.e. there is experimentally derived evidence for the location and function of the proteins), the computational characterization for these families is missing, and the PFAM database ${ }^{33}$ which is the most accurate and complete protein family database, includes only a few profiles from characteristic families. It is worth mentioning that the eukaryotic porin family (PFAM: PF01459) contains two quite different proteins, the voltage-dependent anion channel (VDAC) and the translocase of the outer mitochondrial membrane (TOM40). Even though these two families show high diversity in their amino acid sequences ${ }^{5,34,35}$, they are still classified under the same family in PFAM ${ }^{33}$. Here, we present, a comprehensive computational analysis of eukaryotic transmembrane $\beta$-barrels, where we gathered all the known chloroplastic and mitochondrial $\beta$-barrel families and studied their amino acid sequence characteristics. This analysis is based on a detailed literature search and the construction of specific profiles for each of these families. Finally, we study the frequency of all eukaryotic transmembrane beta barrel families in the reference proteomes of eukaryotic organisms and provide annotation for a large number of previously uncharacterized proteins. 


\section{Material and methods}

In this study we attempt to fully characterize the mitochondrial and chloroplastic OMPs using computational methods. The following workflow describes all the steps followed in this work, starting with building from scratch the characteristic profile HMMs for eukaryotic OMPs, to detecting the eukaryotic OMPs and categorizing these OMPs into 12 different families, four mitochondrial and eight chloroplastic ones.

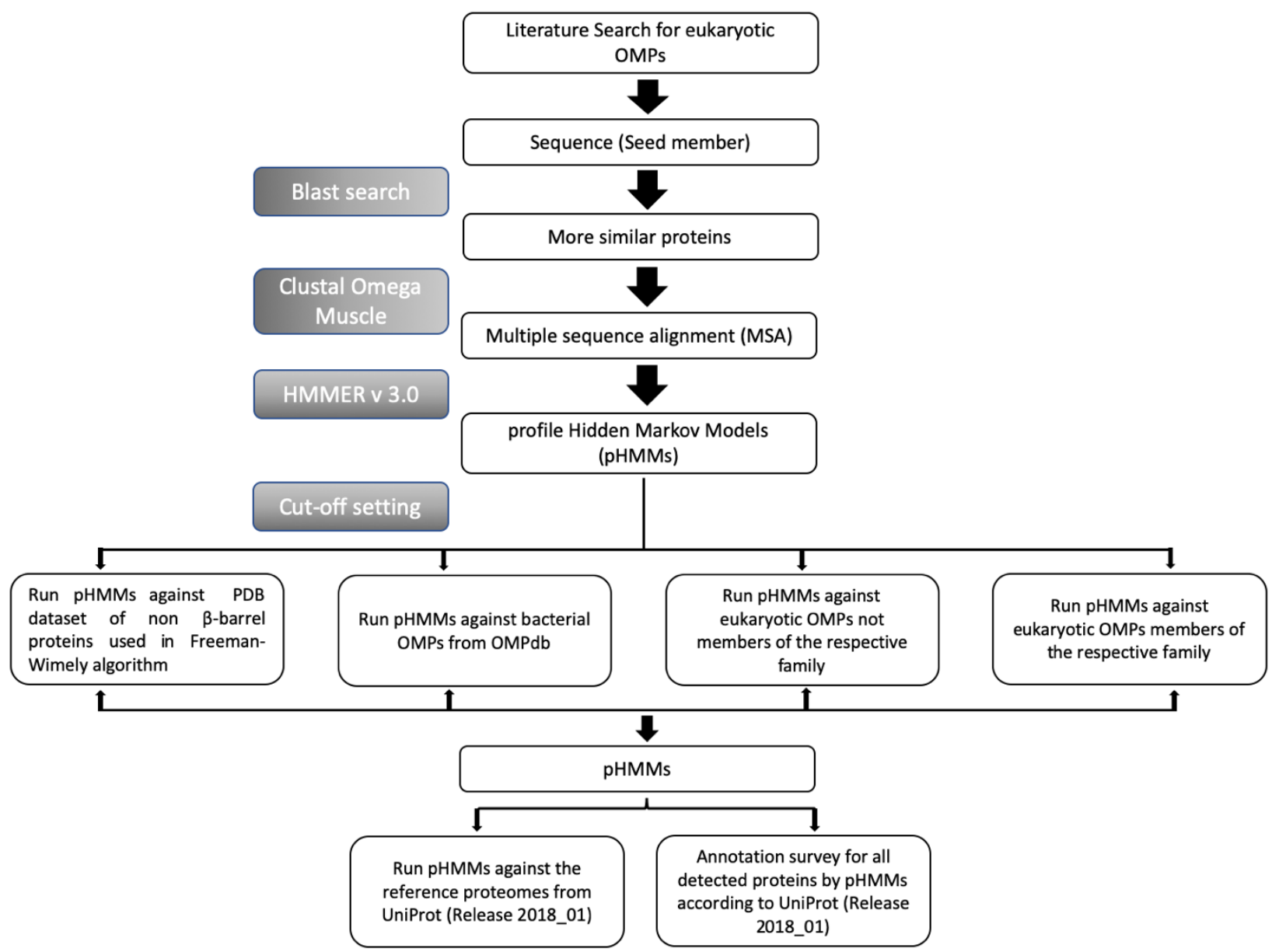

Figure 1 Workflow of the characterization of eukaryotic OMP families.

\subsection{Identification of eukaryotic transmembrane $\beta$-barrels}

To collect all eukaryotic transmembrane $\beta$-barrels, we based our work along three main axes, namely (i) the available 3D structures, (ii) an extensive literature search for novel eukaryotic $\beta$-barrel proteins that are known intrinsically but cannot be retrieved from the databases otherwise, coupled with (iii) investigating the profile 
HMMs (pHMMs) deposited in version 32.0 of the PFAM database ${ }^{33}$, that correspond to domains found solely in eukaryotic $\beta$-barrel proteins.

In PFAM, we found mitochondrial outer membrane proteins under three families: SAM50 (PF01103), MDM10 (PF12519) and, finally, VDAC and TOM40 (PF01459). The SAM50 family (PF01103) contains both bacterial and eukaryotic proteins. We made an attempt to separate the eukaryotic ones and build an independent profile for SAM50 only, but this task proved to be very difficult due to the high similarity between eukaryotic SAM50 proteins and the bacterial ones. Therefore, we decided to use the PF01103 profile as it is. Regarding MDM10, we created a new profile in an attempt to improve the existing one by incorporating novel sequences found in the literature. Also, we created two novel separate profiles for the VDAC and TOM40 families.

Our extensive literature search for the chloroplastic outer membrane proteins resulted in eight protein families (OEP21, OEP23, OEP24, OEP37, OEP40, TGD4, TOC75 and OEP80), members of which were experimentally described as $\beta$-barrel outer membrane proteins (OMPs) using different techniques (CD spectroscopy, subcellular fractionization, immunological and biochemical analysis and channel properties). We need to mention that all the aforementioned chloroplastic families lacked annotation in PFAM.

As a final step, to verify that all these families are transmembrane beta barrels, we used PRED-TMBB2 ${ }^{36}$ to predict the beta barrel domains specifically in those families that did not contain any member with experimentally determined 3D structures.

For all families except TOC75 and OEP80, we used the full length of its members as input in BLAST ${ }^{37}$ search since the barrel part approximately localizes along the full sequences. Regarding TOC75 and OEP80, which are homologues, we took only the beta barrel domains which represent a unique part for each family, then used these domains to create two separated profiles without overlapping.

\subsection{Building the profile HMMs}

We built 11 new profiles, three mitochondrial and eight chloroplastic ones. Two different techniques were used: For all eight chloroplastic families and the MDM10, we initially carried out a BLAST ${ }^{37}$ search against UniProt ${ }^{38}$ using the $\beta$-barrel domain of the experimentally verified protein(s) reported in the respective 
published articles as query. Subsequently, the best-scoring results for each family were used to build Multiple Sequence Alignments (MSAs) with Clustal Omega ${ }^{39}$ and these alignments were refined using MUSCLE ${ }^{40}$. Finally, the profile HMMs were built from the refined alignments using version 3.0 of HMMER ${ }^{41}$. For the VDAC and TOM40 families, we retrieved all the mitochondrial outer membrane proteins via the respective family (PF01459) found in PFAM. Then, we divided the members of this family into three categories, i.e. VDAC, TOM40 and Unknown based on UniProt's annotation. We then gathered all the reviewed gene and protein names for each VDAC and TOM40 member from UniProt ${ }^{38}$. Finally, all redundant sequences were removed and the remaining sequences for each family were used to build the MSAs and, subsequently, the respective pHMMs for the TOM40 and VDAC families, following the same steps described above for the chloroplastic ones and MDM10.

\subsection{Determination of the cut-offs for the profile HMMs}

To calculate the optimal cut-off for each profile, we defined the true positives (TPs) and false positives (FPs) by searching against the test sets with the generated profiles using hmmsearch of the HMMER package. TPs are considered the members of each family that score higher than the threshold value, while members of another family that score higher than the threshold, were considered FPs.

To determine the cut-offs for the chloroplastic profiles and MDM10, all profiles were tested against the following sets: as a positive test set, the members of each family were used (including the ones used to build the pHMM); as negative test sets, two different sets were used: one that includes the proteins from all remaining families and another one derived from OMPdb ${ }^{42}$.

Finally, the score of the highest-scoring known FP was determined, raised by 0.1 and was from then on used as a threshold. In the cases of VDAC and TOM40 families, a 10-fold cross validation was used to identify an optimal discrimination threshold. The sensitivity, specificity and Receiver Operating Characteristic (ROC) curve $^{43}$ for each family were obtained. The score at the cross point of sensitivity with specificity was considered as the optimal discrimination threshold as illustrated in Figure 2.

Consequently, to set the optimal cut-off for VDAC and TOM40, we chose the highest values of sensitivity and specificity together which represents the optimal threshold as shown in Figure 2. Sensitivity refers to the 
proportion of proteins which are correctly classified either VDAC or TOM40 while Specificity refers to the proportion of proteins which are correctly classified neither VDAC nor TOM40.

\subsection{Evaluation of the accuracy of the profile HMMs}

Our next step was to evaluate the capability of profile HMMs to discriminate the eukaryotic transmembrane $\beta$-barrels. To this end, we tested them against two negative datasets: the first negative set is a non-redundant (20\% sequence similarity) PDB dataset of non- $\beta$-barrel proteins, with 7,571 sequences, originating from the dataset used in the Freeman-Wimley algorithm ${ }^{44}$ as it was refined and used in the testing of PRED-TMBB2 algorithm ${ }^{36}$. The second negative set consists of 864,857 bacterial transmembrane $\beta$-barrels from OMPdb ${ }^{42}$.

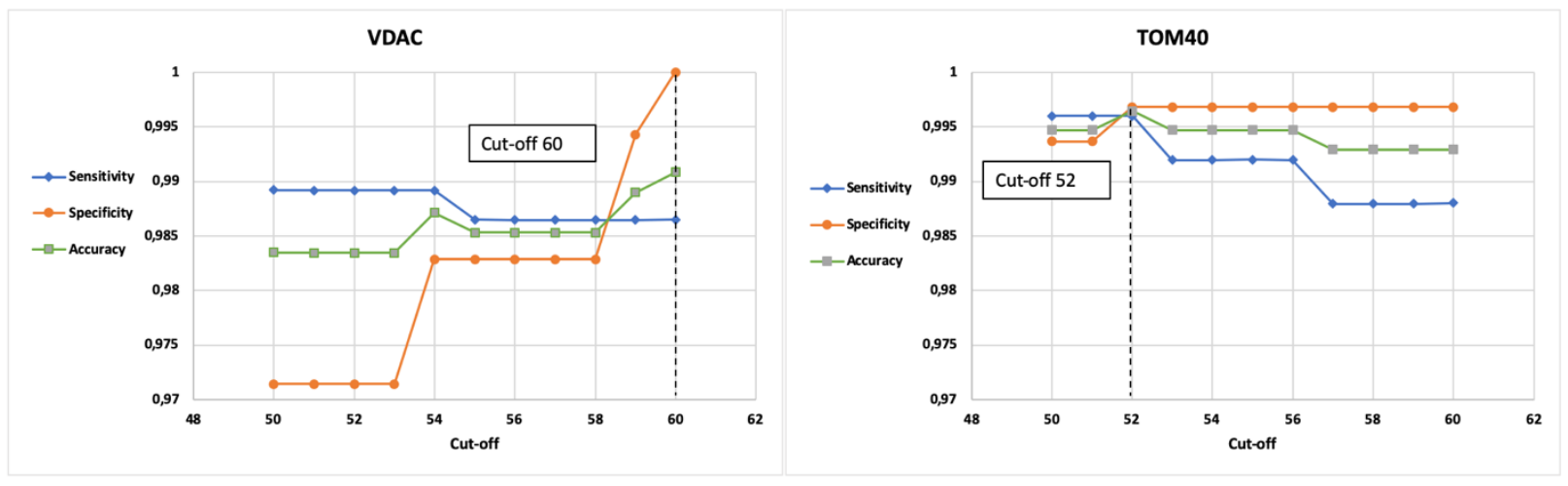

Figure 2. Plot of sensitivity and specificity for the VDAC and TOM40 HMM profiles using different cut-off thresholds.

2.5. Detection of eukaryotic transmembrane $\beta$-barrels in reference proteomes

We downloaded the eukaryotic reference proteomes from UniProt (Release 2018_01) ${ }^{38}$ and performed a search against them using our 11 new profiles (three mitochondrial and eight chloroplastic) and the PF01103 PFAM profile. Finally, we performed a comprehensive survey of the annotation offered in UniProt for all eukaryotic beta barrels detected with our method and evaluated the results. The annotation survey for each family is divided into five categories as follows: "well annotated", refers to any protein with the same gene or protein name of the respective family included based on Uniprot; "mitochondrial" or "chloroplastic", refers to proteins that do not have any gene or protein name but have information about its subcellular location been 
either mitochondrial or chloroplastic based on Uniprot; "uncharacterized", refers to uncharacterized proteins based on Uniprot; "other", refers to any annotation not related to the aforementioned types.

\section{Results}

\subsection{Eukaryotic transmembrane $\beta$-barrels}

The results of the extensive literature search to find all eukaryotic transmembrane $\beta$-barrel families led to the identification of 12 such families (four mitochondrial and eight chloroplastic). The accession numbers of the original member, the experimental method used to determine the beta barrel and the number of strands for these families, are summarized in Table 1. The number of strands for each family may be 1) determined experimentally in the case of proteins with experimentally determined 3D structures (e.g. VDAC and TOM40). In this case, we provide only the number of strands based on the structure. 2) In most cases the number of strands mentioned in the literature is a result of some type of biochemical experiment and/or prediction (e.g. SAM50 and OEP37). In such families, we provide the number of strands mentioned in the respective references and, also, the one from the PRED-TMBB2 prediction we performed. 3) Finally, in few of the families the number of strands is not provided in the literature (e.g. MDM10 and OEP23) and for those we provide only the PREDTMBB2 prediction results.

\subsubsection{Mitochondrial families}

The vast majority of mitochondrial proteins including $\beta$-barrels are encoded by nuclear DNA and synthesized on cytosolic ribosomes. To reach their proper subcellular location, the mitochondrial pre-proteins must have a targeting signal to be decoded by the cell machinery and sent to their correct subcellular destination ${ }^{45,46}$.

The voltage-dependent anion channel (VDAC) exists in the mitochondrial outer membrane of all eukaryotes

47. NMR spectroscopy and X-ray crystallography revealed that VDAC forms a $\beta$-barrel architecture comprised of 19 beta strands ${ }^{48,49}$. In all eukaryotes, VDAC proteins represent the most abundant proteins in the mitochondrial outer membrane (MOM). VDAC has three different but conserved isoforms expressed as VDAC1, VDAC2 and VDAC3 ${ }^{50-52}$ and regulates the movement of metabolites from the cytoplasm to the mitochondrion and vice-versa. Through this function, VDAC organizes various cellular processes like 
metabolism, apoptosis, cellular calcium homeostasis and thus has an effect on several diseases such as cancer, cardiovascular and neurodegenerative diseases ${ }^{53}$.

The translocase of the mitochondrial outer membrane (TOM complex) plays a role as the mitochondrial entry gate for most of nuclear-encoded pre-proteins. A homology model for TOM40 based on an X-ray structure of human VDAC1 proposed a structure with 19 beta strands ${ }^{54}$. Recently, cryo-electron microscopy revealed that the TOM complex is a symmetrical dimer composed of 10 membrane proteins forming a funnel on the surface of the cytoplasmic membrane. Each unit in this dimer consists of a core, which is the 19 beta strands of TOM40, surrounded by TOM5, TOM6 and TOM7 while TOM22 links the two units of the dimer ${ }^{55}$. The complex mediates the translocation of pre-proteins across the MOM via a protein-conducting pore ${ }^{56}$. TOM40 comprises the root of the TOM complex and is the only known mitochondrial outer membrane protein crucial for cell viability ${ }^{57,58}$.

The SAM complex plays a vital role in the integration of $\beta$-barrel proteins into the outer membrane. It consists of SAM50 and two peripheral proteins, SAM35 and SAM37 ${ }^{20,59}$. SAM50 features a single non-membrane polypeptide-transport-associated (POTRA) domain that is not crucial for cell viability ${ }^{20,60,61}$ and, also, a conserved loop six, which promotes $\beta$-signal binding of the pre-proteins to the lateral gate and insertion of next hairpins into the outer membrane ${ }^{62}$. Biochemical studies revealed that SAM50 has a conserved $\beta$-barrel domain -all the way from bacteria to humans ${ }^{63}$. SAM50 forms a 16 -strands $\beta$-barrel in the mitochondrial outer membrane, which has a N-terminal POTRA domain exposed into the intermembrane space ${ }^{64-66}$, whereas the bacterial counterparts are known to possess a 16-stranded barrel, information that is experimentally verified since four members of the OmpIP/Omp85 family have experimentally determined 3D structures ${ }^{67-69} .16$ beta strands were also predicted by PRED-TMBB2.

Table 1. Literature evidence for the eukaryotic transmembrane $\beta$-barrel protein families.

\begin{tabular}{|c|c|c|c|}
\hline Family Category & Accession no. & Experiment ${ }^{(\text {Ref.) }}$ & No. of beta strands (Ref.) \\
\hline VDAC $^{1}$ & P21796 & $\begin{array}{l}\text { NMR spectroscopy and x-ray } \\
\text { crystallography } 48,49\end{array}$ & $19^{48,49}$ \\
\hline TOM $40^{1}$ & P24391 & Electron microscopy ${ }^{55}$ & $19^{55}$ \\
\hline
\end{tabular}




\begin{tabular}{|c|c|c|c|}
\hline $\mathrm{SAM}^{2} 0^{2}$ & P53969 & Biochemical method $^{63}$ & $16^{64-66 / 16^{\text {PRED-TMBB2 }}}$ \\
\hline $\mathrm{MDM} 10^{3}$ & P18409 & $\begin{array}{l}\text { Immunological and } \\
\text { biochemical analysis } 70\end{array}$ & $4^{\text {PRED-TMBB2 }}$ \\
\hline OEP21 ${ }^{2}$ & Q9SM57 & Channel properties ${ }^{24}$ & $8^{24,71} / 8^{\text {PRED-TMBB2 }}$ \\
\hline OEP23 ${ }^{3}$ & A0A088SPC7 & Channel properties ${ }^{25}$ & $8^{\text {PRED-TMBB2 }}$ \\
\hline $\mathrm{OEP}_{2} 4^{2}$ & O49929 & Channel properties ${ }^{26,27}$ & $7^{26,27 / 14^{\text {PRED-TMBB2 }}}$ \\
\hline $\mathrm{OEP}_{3} 7^{2}$ & O80565 & $\begin{array}{l}\text { Channel properties and sub- } \\
\text { cellular fractionization }{ }^{28}\end{array}$ & $12^{72} / 16^{\text {PRED-TMBB2 }}$ \\
\hline $\mathrm{OEP}_{4}{ }^{3}$ & A0A144L7G4 & CD spectroscopy ${ }^{29}$ & $10^{\text {PRED-TMBB2 }}$ \\
\hline TGD4 $^{3}$ & Q9M903 & Subcellular fractionization ${ }^{30}$ & $20^{\text {PRED-TMBB2 }}$ \\
\hline $\mathrm{TOC} 75^{2}$ & Q9STE8 & $\begin{array}{l}\text { Electrophysiological properties } \\
73-75\end{array}$ & $16^{76} / 18^{\text {PRED-TMBB2 }}$ \\
\hline $\mathrm{OEP}^{2} 0^{2}$ & Q9C5J8 & Phylogenetic analysis ${ }^{32}$ & $16^{76-78} / 16^{\text {PRED-TMBB2 }}$ \\
\hline
\end{tabular}

${ }^{1}$ The number of strands based only on an experimentally determined structure.

${ }^{2}$ The number of strands based on evidence from the literature and also on PRED-TMBB2 prediction.

${ }^{3}$ The number of strands based on the PRED-TMBB2 prediction.

MDM10 is a key protein for mitochondrial morphology and inheritance ${ }^{70}$. Immunological and biochemical analysis revealed that MDM10 is an integral outer membrane protein ${ }^{70}$ and homology modelling indicated that it is a $\beta$-barrel protein according to a $\beta$-signal which is required for the biogenesis of $\beta$-barrel proteins ${ }^{79}$. It is predicted to have four transmembrane beta strands by PRED-TMBB2. To our knowledge it is not possible for a protein to form a transmembrane beta barrel consisting of only four strands and that is why the MDM10 family should be further studied. Perhaps the channel formed by MDM10 is multimeric, or perhaps the PRED-TMBB2 algorithm fails to predict the correct number of strands. In any case, the MDM10 barrel formation and its number of strands specifically must be further studied, since all the available literature point to it being a beta barrel protein as we mentioned before.

Along with MMM1 and MDM12, MDM10 enables the connection of mitochondria to the cytoskeleton ${ }^{80}$. MDM10 is also a member of the outer membrane complex that mediates the topogenesis (TOB complex) of precursors of $\beta$-barrel proteins and associated with the assembly of the TOM complex ${ }^{21}$.

\subsubsection{Chloroplastic families}


OEP21 is an anion-selective channel with asymmetric transport characteristics that are adjusted by nucleotides and phosphorylated metabolic intermediates ${ }^{71}$. The biochemical and electrophysiological studies on the OEP21 channel suggested that it contains eight beta strands and has the same topology as OEP24 ${ }^{24}$. According to secondary structure predictions, OEP21 contains eight transmembrane beta strands ${ }^{24,71}$. PREDTMBB2 also predicts 8 transmembrane beta strands.

OEP23 exists in the plant lineage starting from green algae to flowering plants. It is a single channel and is not a member of any multiple pore complex like other bacterial or mitochondrial $\beta$-barrels. For this reason, it is considered a novel member of the ion channels in the outer membrane of chloroplasts that are responsible for solute exchange. CD spectroscopy studies suggest that OEP23 secondary structure contains a low proportion of beta strands ${ }^{25}$.However, PRED-TMBB2 predicted eight transmembrane beta strands in the OEP23 family.

OEP24 forms a high conductance solute track with a diameter of $2.5 \mathrm{~nm}^{26}$. Functional studies stated that the voltage-dependent anion channel can be replaced by OEP24 in yeast mitochondria ${ }^{27}$. Prediction algorithms and CD spectroscopy suggested that OEP24 contains seven amphiphilic beta strands, which is considered as the common secondary structure of mitochondrial and bacterial porins ${ }^{26,81,82}$ but PRED-TMBB2 predicts 14 strands. Moreover, biochemical studies on isolated chloroplast envelope pores revealed that OEP24 composes a homodimer during its active state ${ }^{27}$. OEP24 is not homologous to other mitochondrial or bacterial porins and does not seem to share any structural or functional properties with them. Furthermore, OEP24, when reconstituted into liposomes, creates a voltage-dependent, moderately cation-selective, high conductance channel, which could enable the flux of an assortment of substrates like sugars, dicarboxylic acids, amino acids and ATP through the membrane ${ }^{26}$. Thus, OEP24 could be a multimeric barrel, or more probably, act as homodimer consisting of distinct channels (similar to bacterial porins that form a trimer).

OEP37 is a $\beta$-barrel outer membrane protein found in chloroplasts ${ }^{28}$. Predictions show that it has 12 beta strands and large intermembrane loops ${ }^{72}$. There is a nanomolar affinity between the OEP37 channel and the precursor of Tic32, which is imported into the inner chloroplastic membrane through an unknown pathway. Additionally, it might form a novel peptide-sensitive ion channel in the outer membrane of chloroplasts throughout embryogenesis and germination ${ }^{28}$. PRED-TMBB2 predicted 16 beta strands. 
OEP40 is considered a 'glucose-gate' in the outer membrane of chloroplasts, supporting the movement of selective metabolites between chloroplasts and the neighboring cells. Circular dichroism studies reported that OEP40 has $35.6 \%$ of beta sheets in its structure, and, as a result, it composes a $\beta$-barrel in the outer membrane ${ }^{29}$. OEP40 is predicted to have 10 transmembrane strands by PRED-TMBB2.

TGD4 is conserved evolutionarily from green algae to higher plants ${ }^{83}$ and it is proposed that it is a transmembrane protein, probably a $\beta$-barrel one, present in the outer membrane of the chloroplast with its $\mathrm{N}$ terminus presumably facing the cytoso ${ }^{30}$. Wang et al. revealed that TGD4 appears to form multiple beta strands, particularly near the C-terminus based on secondary structure predictions using PROF ${ }^{84}$. Furthermore, TGD4 appears to have 20 transmembrane beta strands according to PRED-TMBB2.

The Translocon protein found at the outer-envelope-membrane of chloroplasts (TOC75) is a $\beta$-barrel integral membrane protein that belongs to the OMP85 superfamily ${ }^{85}$. It is predicted to have 16 amphiphilic beta strands ${ }^{76}$ and is a key component in the protein translocation pathway on the outer membrane of chloroplasts ${ }^{86}$. POTRA domains of TOC75 together with TIC236 may form a continuous chaperone pathway for the translocation of pre-proteins across the intermembrane space ${ }^{87}$. PRED-TMBB2 predicts that TOC75 has 18 beta strands.

Outer envelope protein 80 (OEP80) is another homolog of OMP85 in plant chloroplasts ${ }^{32}$, whose function is still unclear ${ }^{88}$. It is also referred to as TOC75-V since it is encoded in the V chromosome of Arabidopsis thaliana 77. It is also predicted to have 16 beta strands ${ }^{76-78}$, which is also the number of strands that PRED-TMBB2 predicts. Multiple structural studies in OMP85 homologs have detected a conserved folding pattern of POTRA domains ${ }^{89}$ and the typical antiparallel manner of the transmembrane $\beta$-barrel ${ }^{68,69,90,91}$. Finally, phylogenetic analysis supported the grouping of TOC75 and OEP80 sister to OMP85 ${ }^{32}$. Recently, Gross et al. ${ }^{92}$ showed that OEP80 has a vital role in the insertion of $\beta$-barrel proteins into the chloroplastic outer membrane. They revealed that OEP80 has a cleavable N-terminal signal and, in addition, its POTRA domains are exposed to the intermembrane space of chloroplast. Thus, OEP80 seems to interact with chloroplast substrates.

\subsection{Detection of eukaryotic beta barrels in reference proteomes using pHMMs}

The determined cut-offs, datasets and the length of each HMM profile for the eukaryotic transmembrane $\beta$ barrel families are shown in Table 2. The length of eukaryotic domains ranges from 167 for OEP21 HMM 
profile, which represents the shortest domain, to 472 for TGD4 HMM profile, which is the longest one. These numbers correlate well with the respective ones found in bacterial proteins.

Table 2. The specifications of HMM profiles.

\begin{tabular}{|l|l|l|l|}
\hline Family & Cut-off & Dataset & Length \\
\hline VDAC & 60 & 52 & 281 \\
\hline TOM40 & 52 & 21 & 322 \\
\hline MDM10 & 13.6 & 23 & 346 \\
\hline SAM50 & 20.7 & 46 & 324 \\
\hline OEP21 & 45.5 & 42 & 167 \\
\hline OEP23 & 140.1 & 36 & 205 \\
\hline OEP24 & 25.5 & 40 & 212 \\
\hline OEP37 & 29.8 & 17 & 338 \\
\hline OEP40 & 23.5 & 17 & 378 \\
\hline TGD4 & 47.4 & 51 & 472 \\
\hline TOC75 & 80.9 & 7 & 366 \\
\hline OEP80 & 90 & 9 & 332 \\
\hline
\end{tabular}

Regarding the cut-offs of VDAC and TOM40 HMM profiles, which are 60 and 52 respectively, the intersection between sensitivity and specificity located before the mentioned cut-offs as shown in Figure 2 . However, we chose the mentioned cut-offs because they represent the highest sensitivity and specificity at the same time for both HMM profiles.

To study the ability of the proposed detection method to discriminate the eukaryotic $\beta$-barrel proteins from bacterial and globular ones, we tested it against OMPdb ${ }^{42}$ and a set of globular proteins ${ }^{44}$. Our profiles did not detect any false positive hits in this test with the exception of the SAM50, OEP80 and TOC75 profiles which detected false positive hits from bacterial ones (as one would expect since this profile is built with both eukaryotic and bacterial sequences).

Out of 1064 eukaryotic reference proteomes, our profiles detected at least one protein in $97.18 \%$ of them, reaching a total of 5194 mitochondrial and 1387 chloroplastic ones (Figure 3). 


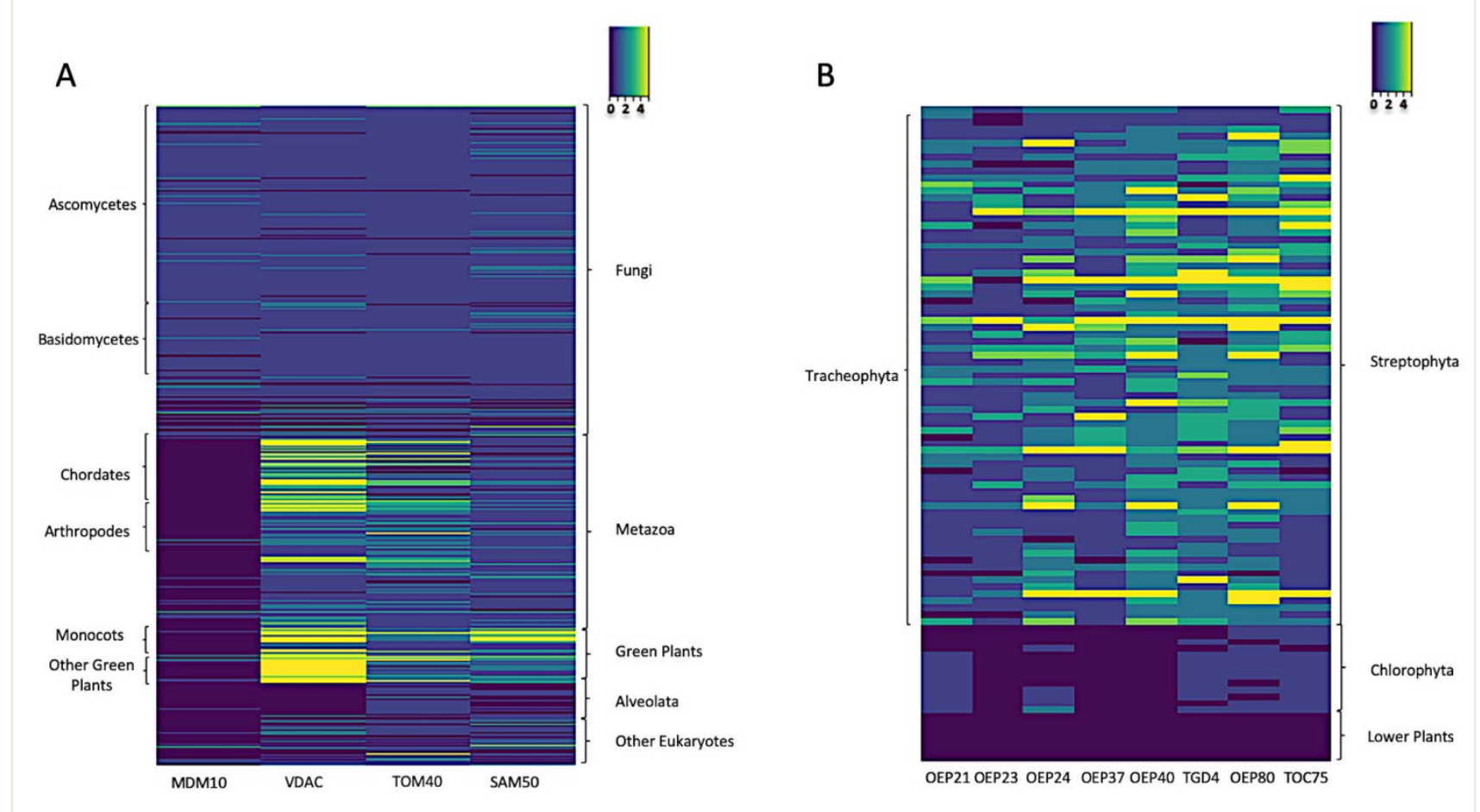

Figure 3. Heatmaps of detected proteins using the eukaryotic pHMMs (A) mitochondrial, (B) chloroplastic.

The chloroplastic and mitochondrial families with the most members detected were OEP80 and VDAC respectively, whereas the families with the fewest members were OEP23 and MDM10 respectively (Figure 4).
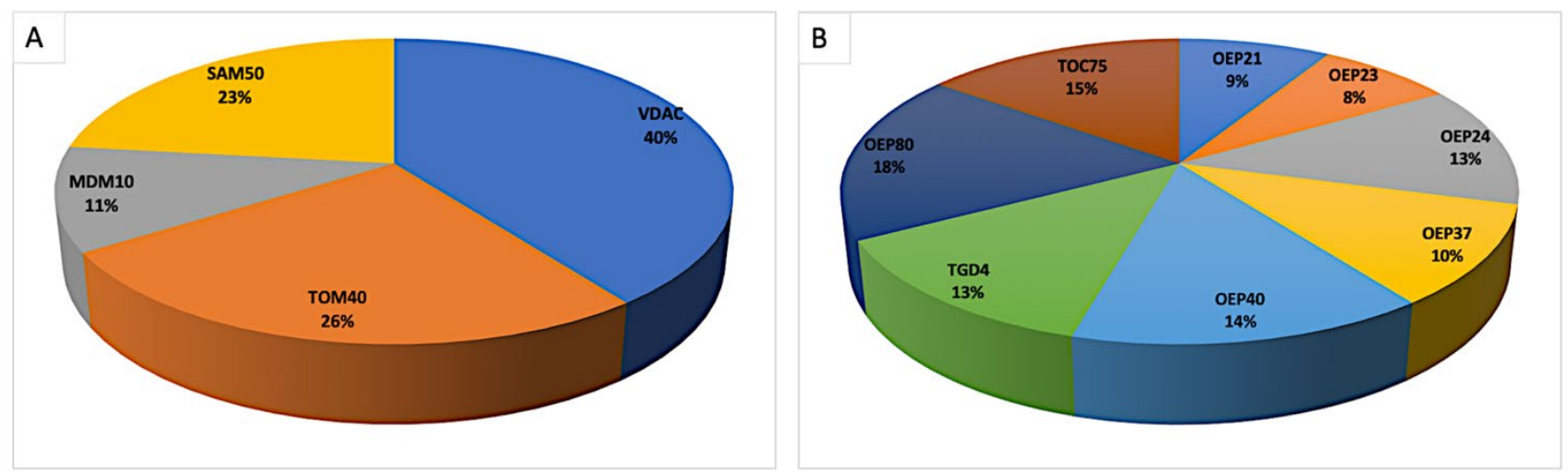

Figure 4. Fractions of detected proteins by eukaryotic pHMMs (A) mitochondrial, (B) chloroplastic.

Regarding the chloroplastic profiles, we found that, in the 96 reference proteomes which contain chloroplasts, our chloroplastic profiles found at least one protein in $90.62 \%$ of them and missed $9.38 \%$.

Concerning the updated mitochondrial pHMM for the MDM10 family, the new pHMM detected 572 proteins while PFAM's PF12519 model detected 518 proteins in the reference proteomes (Figure 5A). 

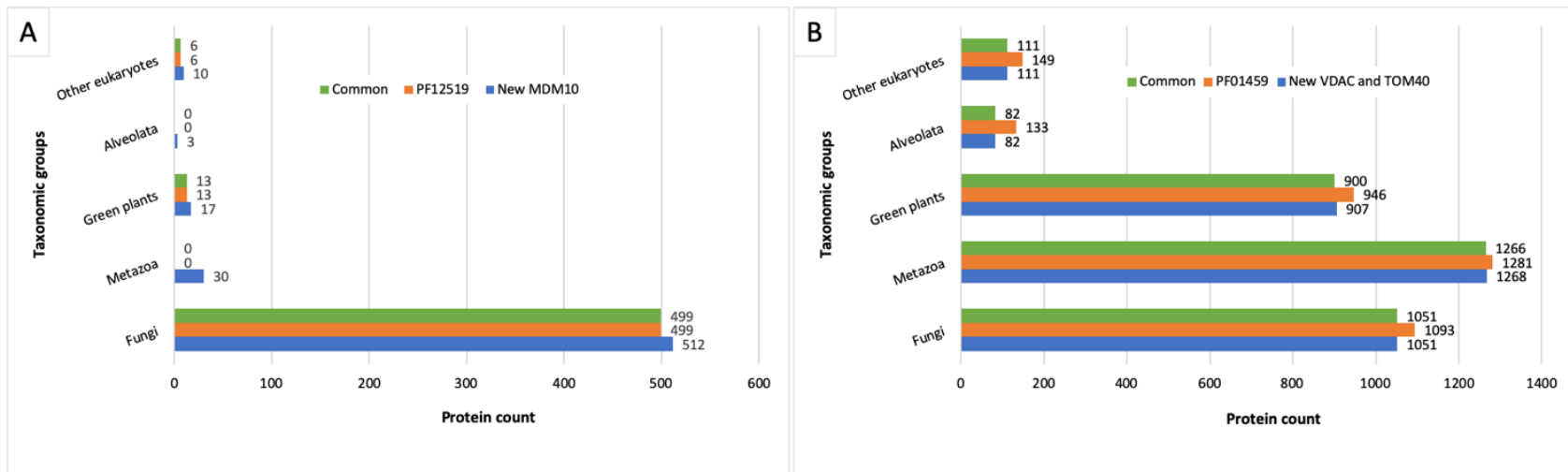

Figure 5. Comparison between detected proteins by updated and PFAM pHMMs for the (A) MDM10 and the (B) Porin_3 family respectively.

The newly built VDAC and TOM40 profiles detected 3419 proteins, but the PF01459 profile detected 3602 proteins in the reference proteomes (Figure 5B). We would like to mention here that there are 3410 common proteins between our new profiles and the PF01459 profile ones. Also, when we checked the 193 missed proteins by our new profiles, we found that only 17 proteins were annotated as VDAC or TOM40 and the other 176 proteins were either "uncharacterized" or of "other annotation". It is important to state that the new MDM10 HMM profile detected all entries which the respective PFAM HMM profile detected or more. On the other hand, the new VDAC and TOM40 HMM profiles detected fewer entries than the Porin_3 HMM profile. However, all detected ones by the new VDAC and TOM40 HMM profiles have been detected by Pfam's Porin_3 profile as well.

Our next step was to analyze the output data from our search using the mitochondrial HMM profiles against the eukaryotic reference proteomes with taxonomic criteria. We categorized the reference proteomes into five taxonomic groups based on NCBI Common Taxonomy Tree ${ }^{93}$. Due to the large number of eukaryotic reference proteomes in the afore-mentioned taxonomic groups, we further categorized our results in taxonomic subgroups and studied the presence of the mitochondrial families in these subgroups (Figure 6).

It is clear that the MDM10 family has the lowest representation in comparison to other mitochondrial families in all taxonomic groups except Fungi, which show similar numbers for all mitochondrial families. $40 \%$ of all detected proteins belong to the VDAC family which comprises the highest portion in comparison to other eukaryotic families (Figure 4A). Additionally, the VDAC family represents the largest fraction in green plants 
(Viridiplantae), Metazoa and Fungi (Figure 6). In most taxonomic groups we detected representatives of both TOM40 and SAM50 families that work synergistically and play a crucial role in the mechanism of translocation. In Mesozoa (1 taxon) we detected only TOM40 members, while in Euglenozoa (19 taxa) and Parabasalia (2 taxa) only SAM50 proteins (Figure 6).

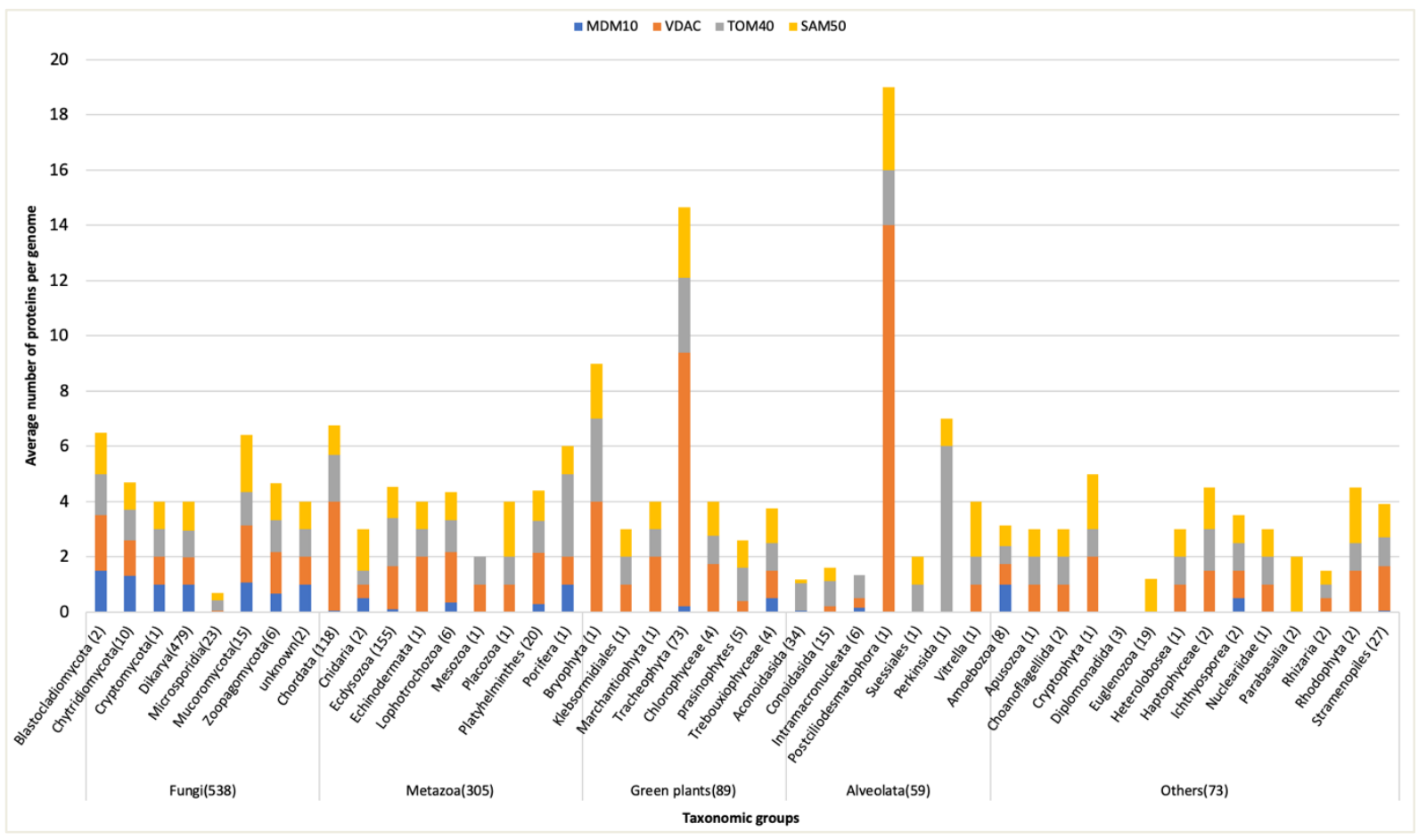

Figure 6. Average number of detected proteins per proteome for the four mitochondrial families.

In our attempt to study the chloroplastic families separately, we categorized all reference proteomes that have chloroplasts into two taxonomic groups based on NCBI Common Taxonomy Tree ${ }^{93}$, i.e. green plants and 'Lower Plants'. We found no members from either of the chloroplastic families in the 'Lower Plants' group. In order to have a better view about the abundance of chloroplastic families in green plants, we followed the taxonomy further down as shown in Figure 7. 


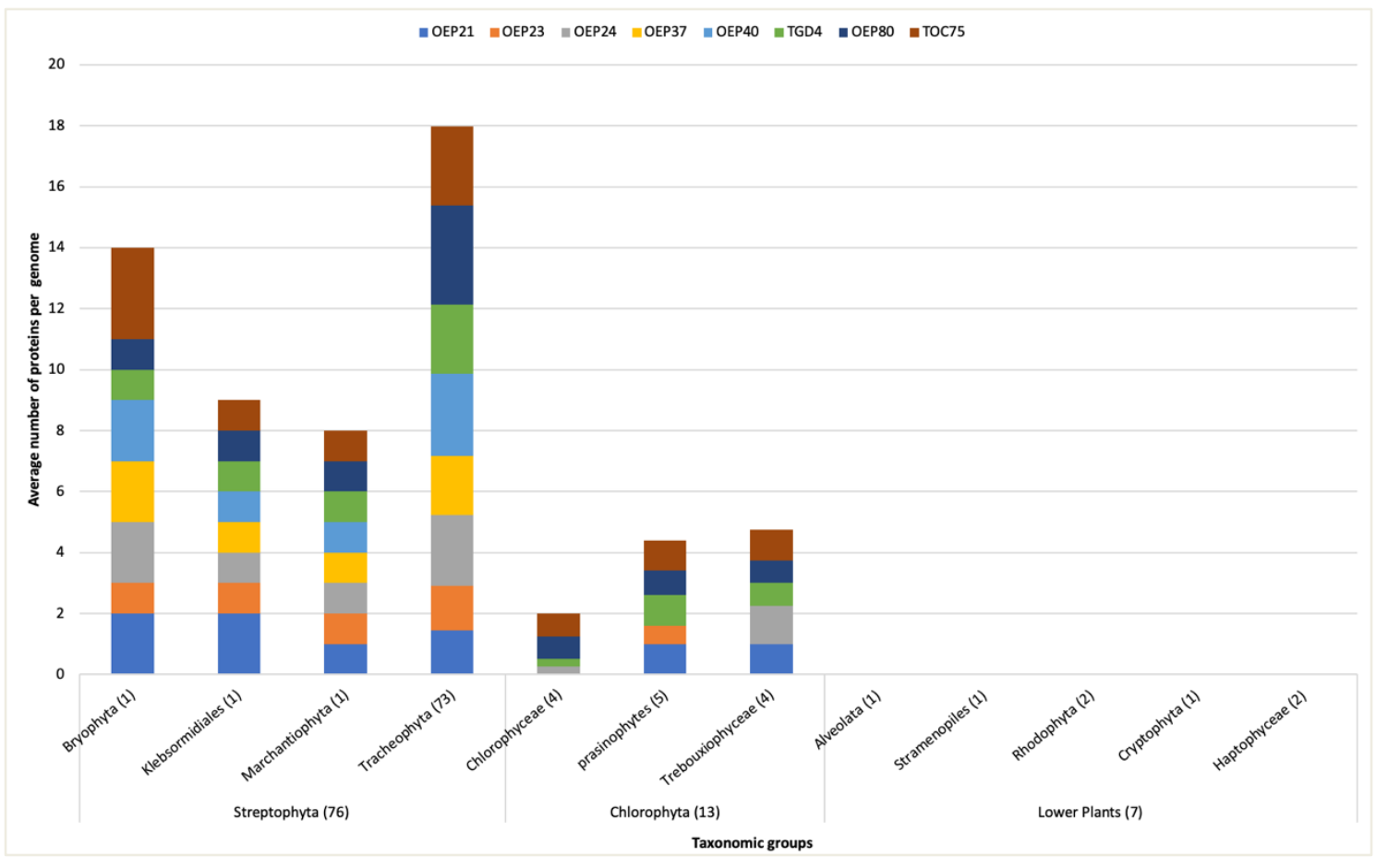

Figure 7. An overview of the average number of detected proteins per proteome for the chloroplastic families.

It is worth mentioning here that in all green plants we detected members of the OEP80 and TOC75 families, proteins that are key players of the translocation pathway of $\beta$-barrel proteins in the outer membrane of chloroplasts.

Lastly, we made a survey for all detected proteins based on their respective UniProt annotation. The annotation results look the same in both mitochondrial and chloroplastic families where the most frequent annotation was the "uncharacterized" with $43.8 \%$ and $71.7 \%$ for mitochondrial and chloroplastic families respectively, followed by the "well annotated" with $38.2 \%$ and $17.8 \%$ for mitochondrial and chloroplastic families respectively, as shown in Figure 8. 

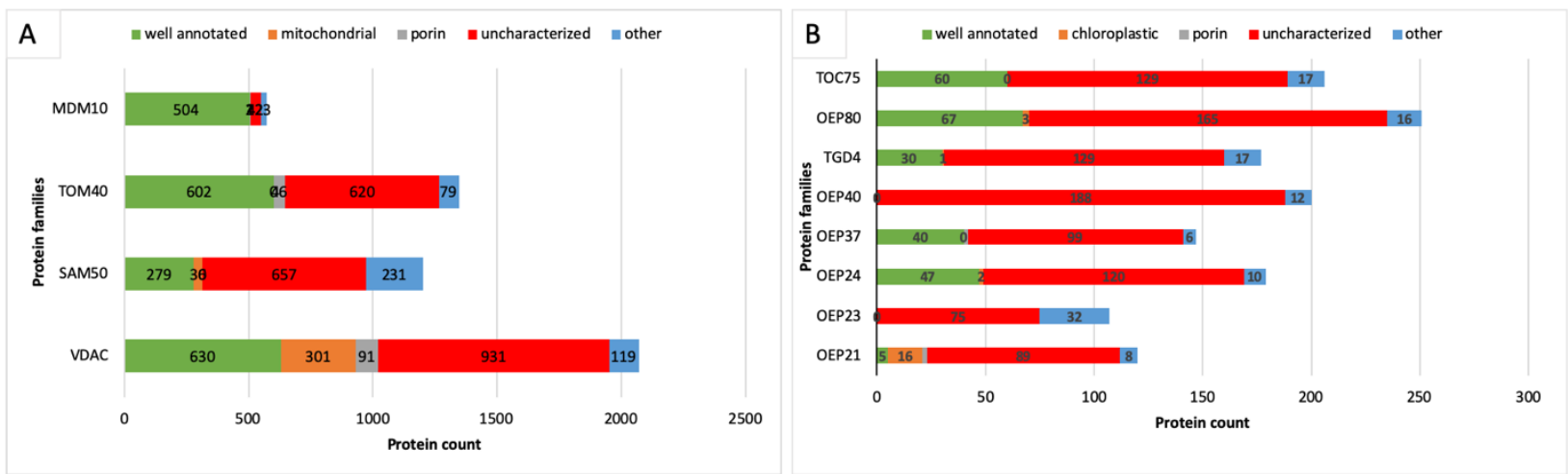

Figure 8. Annotation of the detected proteins by the eukaryotic pHMMs (A) mitochondrial, (B) chloroplastic.

\section{Discussion}

In this work, we presented a comprehensive computational characterization of eukaryotic transmembrane $\beta$ barrel families using a specialized pHMM library. We used four mitochondrial and eight chloroplastic eukaryotic transmembrane $\beta$-barrel protein families that were created based on an extensive literature search and we designed characteristic profiles for each one of them, with the exception of the SAM50 family. Although many of these families were mentioned in the literature (i.e. there is experimentally derived proof for the location and function of the proteins), no method insofar existed that could computationally classify members of these families, and the PFAM database includes only few characteristic profiles. Further, we presented for the first time a complete computational identification of eukaryotic transmembrane $\beta$-barrels in reference proteomes. The profiles that we created follow the rules of PFAM and can be potentially added in the database in the future. As a by-result, we incorporated all the twelve new profiles in the library of profiles that the PRED-TMBB2 tool uses as pre-processing step, in order to possibly improve its prediction performance.

We tried to evaluate the ability of these pHMMs to distinguish the members of each of the 12 families. Using the cut-offs for each profile mentioned in Table 2, our pHMMs did not detect any bacterial transmembrane $\beta$ barrels, nor globular ones, with the exception of SAM50, OEP80 and TOC75 profiles, which detected some bacterial hits, as expected, since the PFAM family (PF01103) contains, also, bacterial proteins. The number of well-characterized eukaryotic SAM50 members proved insufficient in order to build a eukaryotic-specific profile. 
For the mitochondrial families, we updated the MDM10 pHMM and it can now detect more members of the respective family than PFAM's PF12519 model. We built two novel pHMMs for VDAC and TOM40 which detected fewer proteins compared to PF01459, but are able to discriminate between the respective members of these two families. For the VDAC and TOM40 profiles we also tried the HMM-ModE protocol ${ }^{94}$, but the outcome did not differ from the pHMMs built using HMMER. It not our intension to replace the existing PF01459 PFAM model. The two pHMMs were mainly built for the purposes of the present analysis and we suggest that these two novel pHMMs can be used as sub-profiles under the PF01459 profile to characterize VDAC and TOM40 proteins. These three new profiles (MDM10, VDAC and TOM40) are now trained only on eukaryotic proteins from the respective families and when compared with the respective PFAM ones they are more specific.

When using the new mitochondrial profiles and the respective ones from the PFAM database against 1064 reference proteomes, we found that they detected at least one hit in 1034 and 1045 of the proteomes, respectively. It is worth mentioning here that the new profiles failed to detect members in the same reference proteomes in which also the PFAM profiles were unable to find members and in additionally 11 proteomes (as it was perhaps expected).

MDM10 had a marked existence in Fungi, Amoebozoa and Ichtyosporea in comparison to green plants and Metazoa (Figure 6). Our results are in line with Flinner et al., ${ }^{79}$ who found that, MDM10, together with the endoplasmic reticulum mitochondria encounter structure (ERMES) core components like MDM12, MDM34 and MMM1, exist concomitantly in Fungi, Amoebozoa and Filastera (together with Ichtyosporea are classified under the same group Holozoa ${ }^{95}$ ), while they did not detect MDM10 or ERMES cores in neither green plants nor Metazoa. The existence of MDM10 in the aforementioned groups presents its function which appeared earlier during evolution.

In all taxonomic groups except Alveolata (59 taxa) and other eukaryotes (73 taxa), VDAC has the highest fraction and this agrees with other studies, where it was stated that VDAC proteins are the most abundant ones in all eukaryotes ${ }^{50-52}$. Also, VDAC, being the most abundant family in green plants, Metazoa and Fungi is in line with the phylogenetic analysis of Young et. al. ${ }^{96}$, who stated that the paralogs of VDAC have appeared 
many times during its evolution in plants, Metazoan and Fungi, suggesting that this family has no "ancient" paralogs. TOM40 and SAM50 together have representatives in $97.93 \%$ of the studied proteomes (1042 out of 1064 proteomes) and this reflects their crucial biological role in the translocation of OMPs into the MOM in all eukaryotes. This process begins with the translation of mitochondrial OMPs in cytosolic ribosomes and then follows their import into the target organelles ${ }^{61,62,97}$. Mitochondrial proteins reach the mitochondrial surface and then are translocated into the intermembrane space across the outer membrane via the translocase of the MOM (TOM) complex ${ }^{45,98}$. The $\beta$-barrel pre-proteins then interact with TOM20 that can recognize them by their targeting signal consisting of a highly hydrophobic beta hairpin motif ${ }^{4}$. As they pass the outer membrane through a pore formed by TOM40, the core subunits of the TOM complex, TIM8/13 and TIM9/10 prevent the aggregation of the $\beta$-barrel preproteins ${ }^{99}$. Finally, the sorting and assembly machinery (SAM50) facilitates their insertion into the outer membrane depending on the same targeting signal where SAM50 makes a lateral gate between strands 1-16. The signal interacts with beta strand (1) of SAM50 and replaces the beta strand (16) of SAM50. The pre-proteins transfer to the lateral gate is facilitated by the channel lumen of SAM50 (loop 6 located in the channel is required for this process). The pre-proteins stay attached to the SAM50 gate until the folded full-length $\beta$-barrel protein is released and inserted into the $\mathrm{OM}^{62}$.

Regarding the chloroplastic families, three of them were already previously described in the literature but we found and characterized five novel ones. The characterized families are: OEP23, which is related to DUF1990, and two similar families, TOC75 and OEP80 that belong to PF01103. In this work, we updated the OEP23 profile, created two distinct profiles for both TOC75 and OEP80 and, also, built five novel profiles for the other five previously uncharacterized families.

When focusing on the 96 proteomes that contain chloroplasts, our chloroplastic pHMMs detected at least one protein in 89 of them, all belonging to green plants. When we investigated why we did not detect any members in the remaining seven organisms, more questions arose: what are the characteristics of the plastids in these organisms and is there any difference between these plastids and the plastids of green plants?. The answer perhaps lies in the endosymbiotic theory ${ }^{100-102}$. According to this theory, there are two kinds of plastids: A) primary plastids, which are surrounded by two membranes, which existed in Archaeplastida (kingdom Plantae), a major taxonomic group consists of Rhodophyta, Glaucophyta and Chloroplastida (green plants and green 
algae) ${ }^{103} \mathrm{~B}$ ) secondary plastids, which, unlike the aforementioned ones, have a multi-membrane envelope, usually comprised of three (Dinoflagellates ${ }^{104,105}$ ) or four (Cryptophytes ${ }^{106}$ and Haptophytes ${ }^{107}$ ) membranes.

Regarding the two Rhodophyta proteomes ${ }^{108,109}$ in which we were not able to detect any members of the chloroplastic families and which belong to Archaeplastida, these are unicellular organisms and maybe they do not have such proteins or their respective proteins are not that similar to the ones of other green plants. As a final test, we surveyed the protein and gene names of the seven proteomes in an attempt to find any proteins annotated as members of the chloroplastic families described in our study, but we failed to find any. Perhaps this is due to the clear lack of ribosomal DNA repeats in the chloroplasts of Cryptophytes ${ }^{110}$, Haptophytes ${ }^{107,111}$ and Rhodophytes ${ }^{112}$ as described in the respective studies, leading to the inability of these organisms to transcribe the respective genes.

In all green plants we detected members of the OEP80 and TOC75 families, which, together, are crucial for plant viability ${ }^{85}$. In contrast to OEP80, whose function is still unclear, TOC75 represents a substantial component in the translocon at the outer envelope membrane of the chloroplast (TOC) machinery alongside two related GTP-dependent pre-protein receptors, i.e. TOC34 and TOC159. The TOC machinery is responsible for the translocation of OMPs into the chloroplastic outer membrane. The transit peptides of the newly synthesized proteins bind to TOC 34 and TOC159 at the surface of the chloroplast via their GTPase domains. After binding to the two receptors, the translocation of these proteins starts across the membrane through the TOC75 channel passing with a series of intermolecular movements depending on their intrinsic GTPase activities ${ }^{113-115}$.

\section{Conclusions}

In brief, we performed a comprehensive computational analysis for eukaryotic transmembrane $\beta$-barrels using 12 characteristic profile HMMs (eight chloroplastic and four mitochondrial) that can discriminate eukaryotic $\beta$ barrels from other protein classes (globular and bacterial $\beta$-barrels), and also between mitochondrial and chloroplastic ones. Using our profiles, we were able to annotate a large number of previously uncharacterized proteins in the eukaryotic reference proteomes. While trying to characterize the eukaryotic OMPs, we addressed some important points that may form the basis for future studies, like: a) what are the nature and features of the targeting signal that determines the translocation of mitochondrial OMPs into the MOM?, b) do the organisms 
in which we did not detect any chloroplastic beta barrels have such proteins and, if so, what are their features and their evolutionary relation to the known chloroplastic families?

\section{Acknowledgements}

Ahmed F. Roumia is financially supported as a $\mathrm{PhD}$ scholar from a joint program between the ministry of higher education in Egypt and the Greek ministry of foreign affairs (2016/2017). Konstantinos D. Tsirigos was in part supported by the Novo Nordisk Foundation (grant NNF14CC0001). Pantelis G. Bagos and Margarita C. Theodoropoulou are partially supported by the project "ELIXIR-GR: The Greek Research Infrastructure for Data Management and Analysis in Life Sciences" (MIS 5002780) which is implemented under the Action "Reinforcement of the Research and Innovation Infrastructure", funded by the Operational Programme “Competitiveness, Entrepreneurship and Innovation" (NSRF 2014-2020) and co-financed by Greece and the European Union (European Regional Development Fund).

\section{Supporting Information}

A zip file that contains the twelve profile Hidden Markov Models built during this study as well as their seed set alignments for all the eukaryotic transmembrane $\beta$-barrel families is provided as supporting information.

\section{References}

(1) Schulz, G. E. The Structure of Bacterial Outer Membrane Proteins. Biochim. Biophys. Acta 2002, 1565 (2), 308-317.

(2) Fairman, J. W.; Noinaj, N.; Buchanan, S. K. The Structural Biology of $\beta$-Barrel Membrane Proteins: A Summary of Recent Reports. Curr. Opin. Struct. Biol. 2011, 21 (4), 523-531.

(3) Hagan, C. L.; Silhavy, T. J.; Kahne, D. $\beta$-Barrel Membrane Protein Assembly by the Bam Complex. Annu. Rev. Biochem. 2011, 80, 189-210.

(4) Jores, T.; Klinger, A.; Groß, L. E.; Kawano, S.; Flinner, N.; Duchardt-Ferner, E.; Wöhnert, J.; Kalbacher, H.; Endo, T.; Schleiff, E.; et al. Characterization of the Targeting Signal in Mitochondrial 
$\beta$-Barrel Proteins. Nat. Commun. 2016, 27;7:12036.

(5) Paschen, S. A.; Waizenegger, T.; Stan, T.; Preuss, M.; Cyrklaff, M.; Hell, K.; Rapaport, D.; Neupert, W. Evolutionary Conservation of Biogenesis of $\beta$-Barrel Membrane Proteins. Nature 2003, 426 (6968), 862-866.

(6) Voulhoux, R.; Bos, M. P.; Geurtsen, J.; Mols, M.; Tommassen, J. Role of a Highly Conserved Bacterial Protein in Outer Membrane Protein Assembly. Science (80-. ). 2003, 299 (5604), 262-265.

(7) Wiedemann, N.; Kozjak, V.; Chacinska, A.; Schönfisch, B.; Rospert, S.; Ryan, M. T.; Pfanner, N.; Meisinger, C. Machinery for Protein Sorting and Assembly in the Mitochondrial Outer Membrane. Nature 2003, 424 (6948), 565-571.

(8) Wu, T.; Malinverni, J.; Ruiz, N.; Kim, S.; Silhavy, T. J.; Kahne, D. Identification of a Multicomponent Complex Required for Outer Membrane Biogenesis in Escherichia Coli. Cell 2005, 121 (2), 235-245.

(9) Dolezal, P.; Likic, V.; Tachezy, J.; Lithgow, T. Evolution of the Molecular Machines for Protein Import into Mitochondria. Science (80-. ). 2006, 313 (5785), 314-318.

(10) Noinaj, N.; Rollauer, S. E.; Buchanan, S. K. The $\beta$-Barrel Membrane Protein Insertase Machinery from Gram-Negative Bacteria. Curr. Opin. Struct. Biol. 2015, 31, 35-42.

(11) Shoshan-Barmatz, V.; Ben-Hail, D.; Admoni, L.; Krelin, Y.; Tripathi, S. S. The Mitochondrial Voltage-Dependent Anion Channel 1 in Tumor Cells. Biochim. Biophys. Acta-Biomembr. 2015, $1848(10$ Pt, 2547-2575.

(12) Shoshan-Barmatz, V.; Israelson, A.; Brdiczka, D.; Sheu, S. S. The Voltage-Dependent Anion Channel (VDAC): Function in Intracellular Signalling, Cell Life and Cell Death. Curr. Pharm. Des. 2006, 12 (18), 2249-2270.

(13) Schmitt, S.; Prokisch, H.; Schlunck, T.; Camp, D. G.; Ahting, U.; Waizenegger, T.; Scharfe, C.; Meitinger, T.; Imhof, A.; Neupert, W.; et al. Proteome Analysis of Mitochondrial Outer Membrane from Neurospora Crassa. Proteomics 2006, 6 (1), 72-80. 
(14) Zahedi, R. P. Proteomic Analysis of the Yeast Mitochondrial Outer Membrane Reveals Accumulation of a Subclass of Preproteins. Mol. Biol. Cell 2005, 17 (3), 1436-1450.

(15) de Kroon, A. I.; Dolis, D.; Mayer, A.; Lill, R.; de Kruijff, B. Phospholipid Composition of Highly Purified Mitochondrial Outer Membranes of Rat Liver and Neurospora Crassa. Is Cardiolipin Present in the Mitochondrial Outer Membrane? Biochim. Biophys. Acta 1997, 1325 (1), 108-116.

(16) Schneiter, R.; Brügger, B.; Sandhoff, R.; Zellnig, G.; Leber, A.; Lampl, M.; Athenstaedt, K.; Hrastnik, C.; Eder, S.; Daum, G.; et al. Electrospray Ionization Tandem Mass Spectrometry (ESI-MS/MS) Analysis of the Lipid Molecular Species Composition of Yeast Subcellular Membranes Reveals Acyl Chain-Based Sorting/Remodeling of Distinct Molecular Species En Route to the Plasma Membrane. J. Cell Biol. 1999, $146(4), 741-754$.

(17) Zinser, E.; Sperka-Gottlieb, C. D. M.; Fasch, E. V.; Kohlwein, S. D.; Paltauf, F.; Daum, G. Phospholipid Synthesis and Lipid Composition of Subcellular Membranes in the Unicellular Eukaryote Saccharomyces Cerevisiae. J. Bacteriol. 1991, 173 (6), 2026-2034.

(18) Bay, D. C.; Hafez, M.; Young, M. J.; Court, D. A. Phylogenetic and Coevolutionary Analysis of the $\beta$ Barrel Protein Family Comprised of Mitochondrial Porin (VDAC) and Tom40. Biochim. Biophys. Acta - Biomembr. 2012, 1818 (6), 1502-1519.

(19) Ryan, M. T. Chaperones: Inserting Beta Barrels into Membranes. Curr. Biol. 2004, 14, R207-R209.

(20) Kutik, S.; Stojanovski, D.; Becker, L.; Becker, T.; Meinecke, M.; Krüger, V.; Prinz, C.; Meisinger, C.; Guiard, B.; Wagner, R.; et al. Dissecting Membrane Insertion of Mitochondrial $\beta$-Barrel Proteins. Cell 2008, $132(6), 1011-1024$.

(21) Meisinger, C.; Rissler, M.; Chacinska, A.; Sanjuán Szklarz, L. K.; Milenkovic, D.; Kozjak, V.; Schönfisch, B.; Lohaus, C.; Meyer, H. E.; Yaffe, M. P.; et al. The Mitochondrial Morphology Protein Mdm10 Functions in Assembly of the Preprotein Translocase of the Outer Membrane. Dev. Cell 2004, $7(1), 61-71$.

(22) Neuhaus, H. E.; Wagner, R. Solute Pores, Ion Channels, and Metabolite Transporters in the Outer and 
Inner Envelope Membranes of Higher Plant Plastids. Biochim. Biophys. Acta-Biomembr. 2000, 1465 (1-2), 307-323.

(23) Douce, R.; Joyard, J. Biochemistry and Function of the Plastid Envelope. Annu. Rev. Cell Biol. 1990, 6 (1), 173-216.

(24) Hemmler, R.; Becker, T.; Schleiff, E.; Bölter, B.; Stahl, T.; Soll, J.; Götze, T. A.; Braams, S.; Wagner, R. Molecular Properties of Oep21, an ATP-Regulated Anion-Selective Solute Channel from the Outer Chloroplast Membrane. J. Biol. Chem. 2006, 281 (17), 12020-12029.

(25) Goetze, T. A.; Patil, M.; Jeshen, I.; Bölter, B.; Grahl, S.; Soll, J. Oep23 Forms an Ion Channel in the Chloroplast Outer Envelope. BMC Plant Biol. 2015, 15:47.

(26) Pohlmeyer, K.; Soll, J.; Grimm, R.; Hill, K.; Wagner, R. A High-Conductance Solute Channel in the Chloroplastic Outer Envelope from Pea. Plant Cell 1998, 10 (7), 1207-1216.

(27) Röhl, T.; Motzkus, M.; Soll, J. The Outer Envelope Protein OEP24 from Pea Chloroplasts Can Functionally Replace the Mitochondrial VDAC in Yeast. FEBS Lett. 1999, 460 (3), 491-494.

(28) Goetze, T. A.; Philippar, K.; Ilkavets, I.; Soll, J.; Wagner, R. OEP37 Is a New Member of the Chloroplast Outer Membrane Ion Channels. J. Biol. Chem. 2006, 281 (26), 17989-17998.

(29) Harsman, A.; Schock, A.; Hemmis, B.; Wahl, V.; Jeshen, I.; Bartsch, P.; Schlereth, A.; PertlObermeyer, H.; Goetze, T. A.; Soll, J.; et al. OEP40, a Regulated Glucose-Permeable $\beta$-Barrel Solute Channel in the Chloroplast Outer Envelope Membrane. J. Biol. Chem. 2016, 291 (34), 17848-17860.

(30) Wang, Z.; Xu, C.; Benning, C. TGD4 Involved in Endoplasmic Reticulum-to-Chloroplast Lipid Trafficking Is a Phosphatidic Acid Binding Protein. Plant J. 2012, 70 (4), 614-623.

(31) Hinnah, S. C.; Wagner, R.; Sveshnikova, N.; Harrer, R.; Soll, J. The Chloroplast Protein Import Channel Toc75: Pore Properties and Interaction with Transit Peptides. Biophys. J. 2002, 83 (2), 899911.

(32) Day, P. M.; Potter, D.; Inoue, K. Evolution and Targeting of Omp85 Homologs in the Chloroplast 
Outer Envelope Membrane. Front. Plant Sci. 2014, 5:535.

(33) El-Gebali, S.; Mistry, J.; Bateman, A.; Eddy, S. R.; Luciani, A.; Potter, S. C.; Qureshi, M.; Richardson, L. J.; Salazar, G. A.; Smart, A.; et al. The Pfam Protein Families Database in 2019. Nucleic Acids Res. 2019, 47 (D1), D427-D432.

(34) Cavalier-Smith, T. Origin of Mitochondria by Intracellular Enslavement of a Photosynthetic Purple Bacterium. Proc. R. Soc. B Biol. Sci. 2006, 273 (1596), 1943-1952.

(35) Maćašev, D.; Whelan, J.; Newbigin, E.; Silva-Filho, M. C.; Mulhern, T. D.; Lithgow, T. Tom22', an 8KDa Trans-Site Receptor in Plants and Protozoans, Is a Conserved Feature of the TOM Complex That Appeared Early in the Evolution of Eukaryotes. Mol. Biol. Evol. 2004, 21 (8), 1557-1564.

(36) Tsirigos, K. D.; Elofsson, A.; Bagos, P. G. PRED-TMBB2: Improved Topology Prediction and Detection of Beta-Barrel Outer Membrane Proteins. Bioinformatics 2016, 32 (17), i665-i671.

(37) Altschul, S. F.; Madden, T. L.; Schäffer, A. A.; Zhang, J.; Zhang, Z.; Miller, W.; Lipman, D. J. Gapped BLAST and PSI-BLAST: A New Generation of Protein Database Search Programs. Nucleic Acids Res. 1997, 25 (17), 3389-3402.

(38) The UniProt Consortium. UniProt: The Universal Protein Knowledgebase. Nucleic Acids Res. 2017, 45 (D1), D158-D169.

(39) Li, W.; Cowley, A.; Uludag, M.; Gur, T.; McWilliam, H.; Squizzato, S.; Park, Y. M.; Buso, N.; Lopez, R. The EMBL-EBI Bioinformatics Web and Programmatic Tools Framework. Nucleic Acids Res. 2015, 43(W1), W580-4.

(40) Edgar, R. C. MUSCLE: Multiple Sequence Alignment with High Accuracy and High Throughput. Nucleic Acids Res. 2004, 32 (5), 1792-1797.

(41) Eddy, S. R. Profile Hidden Markov Models. Bioinformatics 1998, 14 (9), 755-763.

(42) Tsirigos, K. D.; Bagos, P. G.; Hamodrakas, S. J. OMPdb: A Database of \{beta\}-Barrel Outer Membrane Proteins from Gram-Negative Bacteria. Nucleic Acids Res. 2011, 39 (Database issue), 
D324-31.

(43) Hanley, J. A.; McNeil, B. J. The Meaning and Use of the Area under a Receiver Operating Characteristic (ROC) Curve. Radiology 1982, 143 (1), 29-36.

(44) Freeman, T. C.; Wimley, W. C. A Highly Accurate Statistical Approach for the Prediction of Transmembrane $\beta$-Barrels. Bioinformatics 2010, 26 (16), 1965-1974.

(45) Pfanner, N.; Wiedemann, N.; Meisinger, C.; Lithgow, T. Assembling the Mitochondrial Outer Membrane. Nat. Struct. Mol. Biol. 2004, 11 (11), 1044-1048.

(46) Jensen, R. E.; Dunn, C. D. Protein Import into and across the Mitochondrial Inner Membrane: Role of the TIM23 and TIM22 Translocons. Biochim. Biophys. Acta - Mol. Cell Res. 2002, 1592 (1), 25-34.

(47) Takahashi, Y.; Tateda, C. The Functions of Voltage-Dependent Anion Channels in Plants. Apoptosis 2013, $18(8), 917-924$.

(48) Bayrhuber, M.; Meins, T.; Habeck, M.; Becker, S.; Giller, K.; Villinger, S.; Vonrhein, C.; Griesinger, C.; Zweckstetter, M.; Zeth, K. Structure of the Human Voltage-Dependent Anion Channel. Proc. Natl. Acad. Sci. 2008, 105 (40), 15370-15375.

(49) Hiller, S.; Garces, R. G.; Malia, T. J.; Orekhov, V. Y.; Colombini, M.; Wagner, G. Solution Structure of the Integral Human Membrane Protein VDAC-1 in Detergent Micelles. Science (80-. ). 2008, 321 (5893), 1206-1210.

(50) Benz, R. Permeation of Hydrophilic Solutes through Mitochondrial Outer Membranes: Review on Mitochondrial Porins. BBA - Rev. Biomembr. 1994, 1197 (2), 167-196.

(51) Colombini, M. VDAC: The Channel at the Interface between Mitochondria and the Cytosol. Mol. Cell. Biochem. 2004, 256-257 (1-2), 107-115.

(52) Shoshan-Barmatz, V.; De Pinto, V.; Zweckstetter, M.; Raviv, Z.; Keinan, N.; Arbel, N. VDAC, a Multi-Functional Mitochondrial Protein Regulating Cell Life and Death. Mol. Aspects Med. 2010, 31 (3), 227-285. 
(53) Mazure, N. M. VDAC in Cancer. Biochim. Biophys. acta. Bioenerg. 2017, 1858 (8), 665-673.

(54) Ujwal, R.; Cascio, D.; Colletier, J.-P.; Faham, S.; Zhang, J.; Toro, L.; Ping, P.; Abramson, J. The Crystal Structure of Mouse VDAC1 at 2.3 A Resolution Reveals Mechanistic Insights into Metabolite Gating. Proc. Natl. Acad. Sci. 2008, 105 (46), 17742-17747.

(55) Bausewein, T.; Mills, D. J.; Langer, J. D.; Nitschke, B.; Nussberger, S.; Kühlbrandt, W. Cryo-EM Structure of the TOM Core Complex from Neurospora Crassa. Cell 2017, 170 (4), 693-700.

(56) Walther, D. M.; Rapaport, D. Biogenesis of Mitochondrial Outer Membrane Proteins. Biochim. Biophys. Acta - Mol. Cell Res. 2009, 1793 (1), 42-51.

(57) Ahting, U.; Thieffry, M.; Engelhardt, H.; Hegerl, R.; Neupert, W.; Nussberger, S. Tom40, the PoreForming Component of the Protein-Conducting TOM Channel in the Outer Membrane of Mitochondria. J. Cell Biol. 2001, 153 (6), 1151-1160.

(58) Gabriel, K.; Egan, B.; Lithgow, T. Tom40, the Import Channel of the Mitochondrial Outer Membrane, Plays an Active Role in Sorting Imported Proteins. EMBO J. 2003, 22 (10), 2380-2386.

(59) Lithgow, N. C. C. and T. The Peripheral Membrane Subunits of the SAM Complex Function Codependently in Mitochondrial Outer Membrane Biogenesis. Mol. Biol. Cell 2007, 19 (1), 126-136.

(60) Habib, S. J.; Waizenegger, T.; Niewienda, A.; Paschen, S. A.; Neupert, W.; Rapaport, D. The NTerminal Domain of Tob55 Has a Receptor-like Function in the Biogenesis of Mitochondrial $\beta$-Barrel Proteins. J. Cell Biol. 2007, $176(1), 77-88$.

(61) Pfitzner, A.-K.; Steblau, N.; Ulrich, T.; Oberhettinger, P.; Autenrieth, I. B.; Schütz, M.; Rapaport, D. Mitochondrial-Bacterial Hybrids of BamA/Tob55 Suggest Variable Requirements for the Membrane Integration of $\beta$-Barrel Proteins. Sci. Rep. 2016, 6 (1), 39053.

(62) Höhr, A. I. C.; Lindau, C.; Wirth, C.; Qiu, J.; Stroud, D. A.; Kutik, S.; Guiard, B.; Hunte, C.; Becker, T.; Pfanner, N.; et al. Membrane Protein Insertion through a Mitochondrial $\beta$-Barrel Gate. Science (80.). 2018, 359 (6373), eaah6834. 
(63) Kozjak, V.; Wiedemann, N.; Milenkovic, D.; Lohaus, C.; Meyer, H. E.; Guiard, B.; Meisinger, C.; Pfanner, N. An Essential Role of Sam50 in the Protein Sorting and Assembly Machinery of the Mitochondrial Outer Membrane. J. Biol. Chem. 2003, 278 (49), 48520-48523.

(64) Klein, A.; Israel, L.; Lackey, S. W. K.; Nargang, F. E.; Imhof, A.; Baumeister, W.; Neupert, W.; Thomas, D. R. Characterization of the Insertase for $\beta$-Barrel Proteins of the Outer Mitochondrial Membrane. J. Cell Biol. 2012, 199 (4), 599-611.

(65) Sánchez-Pulido, L.; Devos, D.; Genevrois, S.; Vicente, M.; Valencia, A. POTRA: A Conserved Domain in the FtsQ Family and a Class of $\beta$-Barrel Outer Membrane Proteins. Trends Biochem. Sci. 2003, $28(10), 523-526$.

(66) Zeth, K. Structure and Evolution of Mitochondrial Outer Membrane Proteins of $\beta$-Barrel Topology. Biochim. Biophys. Acta - Bioenerg. 2010, 1797 (6-7), 1292-1299.

(67) Albrecht, R.; Schütz, M.; Oberhettinger, P.; Faulstich, M.; Bermejo, I.; Rudel, T.; Diederichs, K.; Zeth, K. Structure of BamA, an Essential Factor in Outer Membrane Protein Biogenesis. Acta Crystallogr. Sect. D Biol. Crystallogr. 2014.

(68) Gruss, F.; Zähringer, F.; Jakob, R. P.; Burmann, B. M.; Hiller, S.; Maier, T. The Structural Basis of Autotransporter Translocation by TamA. Nat. Struct. Mol. Biol. 2013, 20 (11), 1318-1320.

(69) Noinaj, N.; Kuszak, A. J.; Gumbart, J. C.; Lukacik, P.; Chang, H.; Easley, N. C.; Lithgow, T.; Buchanan, S. K. Structural Insight into the Biogenesis of $\beta$-Barrel Membrane Proteins. Nature 2013, 501 (7467), 385-390.

(70) Sogo, L. F.; Yaffe, M. P. Regulation of Mitochondrial Morphology and Inheritance by Mdm10p, a Protein of the Mitochondrial Outer Membrane. J. Cell Biol. 1994, 126 (6), 1361-1373.

(71) Bölter, B.; Soll, J.; Hill, K.; Hemmler, R.; Wagner, R. A Rectifying ATP-Regulated Solute Channel in the Chloroplastic Outer Envelope from Pea. EMBO J. 1999, 18 (20), 5505-5516.

(72) Schleiff, E. Prediction of the Plant Beta-Barrel Proteome: A Case Study of the Chloroplast Outer 
Envelope. Protein Sci. 2003, 12 (4), 748-759.

(73) Schleiff, E.; Maier, U. G.; Becker, T. Omp85 in Eukaryotic Systems: One Protein Family with Distinct Functions. Biol. Chem. 2011, 392(1-2), 21-27.

(74) Soll, J.; Schleiff, E. Protein Import into Chloroplasts. Nat. Rev. Mol. Cell Biol. 2004, 9 (6), $222-227$.

(75) Schleiff, E.; Becker, T. Common Ground for Protein Translocation: Access Control for Mitochondria and Chloroplasts. Nat. Rev. Mol. Cell Biol. 2011, 12 (1), 48-59.

(76) Sveshnikova, N.; Grimm, R.; Soll, J.; Schleiff, E. Topology Studies of the Chloroplast Protein Import Channel Toc75. Biol. Chem. 2000, 381 (8), 687-693.

(77) Eckart, K.; Eichacker, L.; Sohrt, K.; Schleiff, E.; Heins, L.; Soll, J. A Toc75-like Protein Import Channel Is Abundant in Chloroplasts. EMBO Rep. 2002, 3 (6), 557-562.

(78) Inoue, K.; Potter, D. The Chloroplastic Protein Translocation Channel Toc75 and Its Paralog OEP80 Represent Two Distinct Protein Families and Are Targeted to the Chloroplastic Outer Envelope by Different Mechanisms. Plant J. 2004, 39 (3), 354-365.

(79) Flinner, N.; Ellenrieder, L.; Stiller, S. B.; Becker, T.; Schleiff, E.; Mirus, O. Mdm10 Is an Ancient Eukaryotic Porin Co-Occurring with the ERMES Complex. Biochim. Biophys. Acta-Mol. Cell Res. 2013, 1833 (12), 3314-3325.

(80) Boldogh, I. R. A Protein Complex Containing Mdm10p, Mdm12p, and Mmm1p Links Mitochondrial Membranes and DNA to the Cytoskeleton-Based Segregation Machinery. Mol. Biol. Cell 2003, 14 (11), 4618-4627.

(81) Cowan, S. W.; Schirmer, T.; Rummel, G.; Steiert, M.; Ghosh, R.; Pauptit, R. A.; Jansonius, J. N.; Rosenbusch, J. P. Crystal Structures Explain Functional Properties of Two E. Coli Porins. Nature 1992, 358 (6389), 727-733.

(82) De Pinto, V.; Prezioso, G.; Palmieri, F.; Thinnes, F.; Link, T. A. Peptide-Specific Antibodies and Proteases as Probes of the Transmembrane Topology of the Bovine Heart Mitochondrial Porin. 
Biochemistry 1991, 30 (42), 10191-10200.

(83) Xu, C.; Fan, J.; Cornish, A. J.; Benning, C. Lipid Trafficking between the Endoplasmic Reticulum and the Plastid in Arabidopsis Requires the Extraplastidic TGD4 Protein. PLANT CELL ONLINE 2008, 20 (8), 2190-2204.

(84) Rost, B.; Yachdav, G.; Liu, J. The PredictProtein Server. Nucleic Acids Res. 2004, 32 (Web Server issue), W321-6.

(85) Hsu, S. C.; Inoue, K. Two Evolutionarily Conserved Essential $\beta$-Barrel Proteins in the Chloroplast Outer Envelope Membrane. Biosci. Trends 2009, 3 (5), 168-178.

(86) Baldwin, A. A Molecular-Genetic Study of the Arabidopsis Toc75 Gene Family. PLANT Physiol. 2005, $138(2), 715-733$.

(87) Chen, Y.-L.; Chen, L.-J.; Chu, C.-C.; Huang, P.-K.; Wen, J.-R.; Li, H. TIC236 Links the Outer and Inner Membrane Translocons of the Chloroplast. Nature 2018, 564 (7734), 125-129.

(88) Inoue, K. Emerging Roles of the Chloroplast Outer Envelope Membrane. Trends Plant Sci. 2011, 16 (10), 550-557.

(89) Simmerman, R. F.; Dave, A. M.; Bruce, B. D. Structure and Function of POTRA Domains of Omp85/TPS Superfamily. Int. Rev. Cell Mol. Biol. 2014, 308, 1-34.

(90) Ni, D.; Wang, Y.; Yang, X.; Zhou, H.; Hou, X.; Cao, B.; Lu, Z.; Zhao, X.; Yang, K.; Huang, Y. Structural and Functional Analysis of the $\beta$-Barrel Domain of BamA from Escherichia Coli. FASEB J. 2014, 28 (6), 2677-2685.

(91) Clantin, B.; Delattre, A. S.; Rucktooa, P.; Saint, N.; Méli, A. C.; Locht, C.; Jacob-Dubuisson, F.; Villeret, V. Structure of the Membrane Protein FhaC: A Member of the Omp85-TpsB Transporter Superfamily. Science (80-. ). 2007, 317 (5840), 957-961.

(92) Gross, L. E.; Spies, N.; Simm, S.; Schleiff, E. Toc75-V/OEP80 Is Processed during Translocation into Chloroplasts and the Membrane Embedded Form Exposes Its POTRA Domain to the Intermembrane 
Space. FEBS Open Bio 2020.

(93) Sayers, E. W.; Barrett, T.; Benson, D. A.; Bryant, S. H.; Canese, K.; Chetvernin, V.; Church, D. M.; DiCuccio, M.; Edgar, R.; Federhen, S.; et al. Database Resources of the National Center for Biotechnology Information. Nucleic Acids Res. 2009, 37 (Database), D5-D15.

(94) Srivastava, P. K.; Desai, D. K.; Nandi, S.; Lynn, A. M. HMM-ModE - Improved Classification Using Profile Hidden Markov Models by Optimising the Discrimination Threshold and Modifying Emission Probabilities with Negative Training Sequences. BMC Bioinformatics 2007, 8:104.

(95) Lang, B. F.; O’Kelly, C.; Nerad, T.; Gray, M. W.; Burger, G. The Closest Unicellular Relatives of Animals. Curr. Biol. 2002, 12 (20), 1773-1778.

(96) Young, M. J.; Bay, D. C.; Hausner, G.; Court, D. A. The Evolutionary History of Mitochondrial Porins. BMC Evol. Biol. 2007, 7:31.

(97) Ulrich, T.; Rapaport, D. Biogenesis of Beta-Barrel Proteins in Evolutionary Context. Int. J. Med. Microbiol. 2015, 305 (2), 259-264.

(98) Rapaport, D.; Neupert, W. Biogenesis of Tom40, Core Component of the TOM Complex of Mitochondria. J. Cell Biol. 1999, 146 (2), 321-331.

(99) Wiedemann, N.; Truscott, K. N.; Pfannschmidt, S.; Guiard, B.; Meisinger, C.; Pfanner, N. Biogenesis of the Protein Import Channel Tom40 of the Mitochondrial Outer Membrane: Intermembrane Space Components Are Involved in an Early Stage of the Assembly Pathway. J. Biol. Chem. 2004, 279 (18), $18188-18194$.

(100) Oborník, M. In the Beginning Was the Word: How Terminology Drives Our Understanding of Endosymbiotic Organelles. Microb. Cell 2019, 6 (2), 134-141.

(101) CAVAliER-SMITH, T.; LEE, J. J. Protozoa as Hosts for Endosymbioses and the Conversion of Symbionts into Organelles,. In The Journal of Protozoology; 1985; Vol. 32, pp 376-379.

(102) Gould, S. B.; Waller, R. F.; McFadden, G. I. Plastid Evolution. Annu. Rev. Plant Biol. 2008, 59 (1), 
491-517.

(103) Adl, S. M.; Simpson, A. G. B.; Lane, C. E.; Lukeš, J.; Bass, D.; Bowser, S. S.; Brown, M. W.; Burki, F.; Dunthorn, M.; Hampl, V.; et al. The Revised Classification of Eukaryotes. J. Eukaryot. Microbiol. 2012, $59(5), 429-493$.

(104) LaJeunesse, T. C.; Parkinson, J. E.; Gabrielson, P. W.; Jeong, H. J.; Reimer, J. D.; Voolstra, C. R.; Santos, S. R. Systematic Revision of Symbiodiniaceae Highlights the Antiquity and Diversity of Coral Endosymbionts. Curr. Biol. 2018, 28 (16), 2570-2580.e6.

(105) Pasaribu, B.; Weng, L. C.; Lin, I. P.; Camargo, E.; Tzen, J. T. C.; Tsai, C. H.; Ho, S. L.; Lin, M. R.; Wang, L. H.; Chen, C. S.; et al. Morphological Variability and Distinct Protein Profiles of Cultured and Endosymbiotic Symbiodinium Cells Isolated from Exaiptasia Pulchella. Sci. Rep. 2015, 5:15353.

(106) Onuma, R.; Mishra, N.; Miyagishima, S. Y. Regulation of Chloroplast and Nucleomorph Replication by the Cell Cycle in the Cryptophyte Guillardia Theta. Sci. Rep. 2017, 7 (1), 2345.

(107) Puerta, M. V. S.; Bachvaroff, T. R.; Delwiche, C. F. The Complete Plastid Genome Sequence of the Haptophyte Emiliania Huxleyi: A Comparison to Other Plastid Genomes. DNA Res. 2005, 12 (2), 151156.

(108) McFadden, G. I.; Van Dooren, G. G. Evolution: Red Algal Genome Affirms a Common Origin of All Plastids. Curr. Biol. 2004, 14 (13), R514-6.

(109) Jain, K.; Krause, K.; Grewe, F.; Nelson, G. F.; Weber, A. P. M.; Christensen, A. C.; Mower, J. P. Extreme Features of the Galdieria Sulphuraria Organellar Genomes: A Consequence of Polyextremophily. Genome Biol. Evol. 2014, 7 (1), 367-380.

(110) Douglas, S. E.; Penny, S. L. The Plastid Genome of the Cryptophyte Alga, Guillardia Theta: Complete Sequence and Conserved Synteny Groups Confirm Its Common Ancestry with Red Algae. J. Mol. Evol. 1999, 48 (2), 236-244.

(111) Hovde, B. T.; Starkenburg, S. R.; Hunsperger, H. M.; Mercer, L. D.; Deodato, C. R.; Jha, R. K.; 
Chertkov, O.; Monnat, R. J.; Cattolico, R. A. The Mitochondrial and Chloroplast Genomes of the Haptophyte Chrysochromulina Tobin Contain Unique Repeat Structures and Gene Profiles. BMC Genomics 2014, 15:604.

(112) Reith, M.; Munholland, J. The Ribosomal RNA Repeats Are Non-Identical and Directly Oriented in the Chloroplast Genome of the Red Alga Porphyra Purpurea. Curr. Genet. 1993, 24 (5), 443-450.

(113) Kessler, F.; Schnell, D. J. A Gtpase Gate for Protein Import into Chloroplasts. Nat. Struct. Biol. 2002, $9(2), 81-83$.

(114) Kikuchi, S.; Hirohashi, T.; Nakai, M. Characterization of the Preprotein Translocon at the Outer Envelope Membrane of Chloroplasts by Blue Native PAGE. Plant Cell Physiol. 2006, 47 (3), 363-371.

(115) Chen, K. Y.; Li, H. M. Precursor Binding to an 880-KDa Toc Complex as an Early Step during Active Import of Protein into Chloroplasts. Plant J. 2007, 49 (1), 149-158. 
For Table of Contents Only

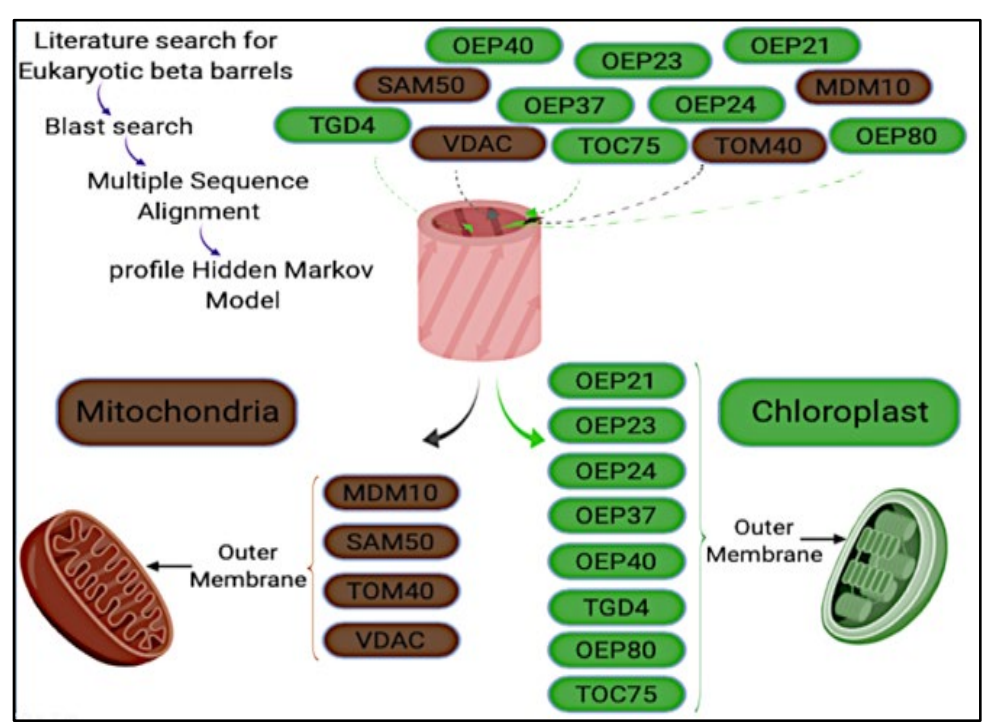

